\title{
A Role of Zonal Gradient of SST between the Indian Ocean and the Western Pacific in Localized Convection around the Philippines
}

\author{
Masamichi Ohba and Hiroaki Ueda \\ Graduate School of Life and Environmental Sciences, University of Tsukuba, Tsukuba, Japan.
}

\begin{abstract}
Interannual fluctuations of the convective activity around the Philippines are highly correlated with the east-west gradient of SST between the North Indian Ocean (NIO) and the western North Pacific (WNP). We conducted a set of experiments by use of an atmospheric general circulation model (AGCM) to assess the relative importance of the remote (NIO) versus in situ (WNP) SST anomalies in determining the WNP monsoon rainfall as ocean-to-atmosphere feedback. The solutions indicate that both in situ and remote SST anomalies regulate precipitation around the Philippines in the early summer. This result implies that the WNP monsoon rainfall is sensitive to the spatial distribution of the NIO SST anomalies as well as the in situ anomalies. These physical interpretations suggest further increase of the predictability in the WNP monsoon.
\end{abstract}

\section{Introduction}

A number of numerical studies have attempted to address a role of anomalous sea surface conditions in contributing to the summer monsoon circulation and precipitation. It is widely recognized that sea surface temperature (SST) anomalies in the Indian Ocean could affect the monsoon precipitation mainly through changes in evaporation and the low-level moisture source. Chandrasekar and Kitoh (1998) specified positive SST anomalies near the equatorial Indian Ocean and showed a local increase of the Asian summer monsoon (ASM) westerlies, while a reduction in monsoon rainfall over the south Asian land areas. Wang et al. (2000) reveals the importance of the local air-sea interaction on the precipitation over the East Asia. In addition to the influence of the local SST anomalies, the recent studies examine in situ versus remote SST influences on the variation of precipitation over the East Asia, especially around the Philippines (e.g., Nakazawa 2001; Terao and Kubota 2005). They argued that the East Asian summer monsoon is influenced not only by the local SST but also by the remote SST anomalies.

Kawamura et al. (1998) performed 40-year atmospheric general circulation model (AGCM) simulations employing prescribed observed SST, and showed that anomalous east-west asymmetric SST across the Philippines is crucially responsible for the frequent occurrence of the extreme summers in the East Asia. By using an oceanic general circulation model, furthermore, Kawamura et al. (2001) succeeded to reproduce the eastwest gradient of summer-time SST anomalies that is associated with the ASM intensity. In the strong ASM year, the North Indian Ocean (NIO) and South China Sea (SCS) are covered by cool SST anomalies due to enhanced surface wind speed and evaporation, whereas warm anomalies are maintained in the warm pool region of the western North Pacific (WNP). They

Corresponding author: Masamichi Ohba, Graduate School of Life and Environmental Sciences, University of Tsukuba, 1-1-1 Tennohdai, Tsukuba, Ibaraki, 305-8572, Japan. E-mail: s0430256@ipe.tsukuba.ac.jp. @2006, the Meteorological Society of Japan.
Correlation of Philippine OLR (June: 130-140E, 5-15N) on Obs SST
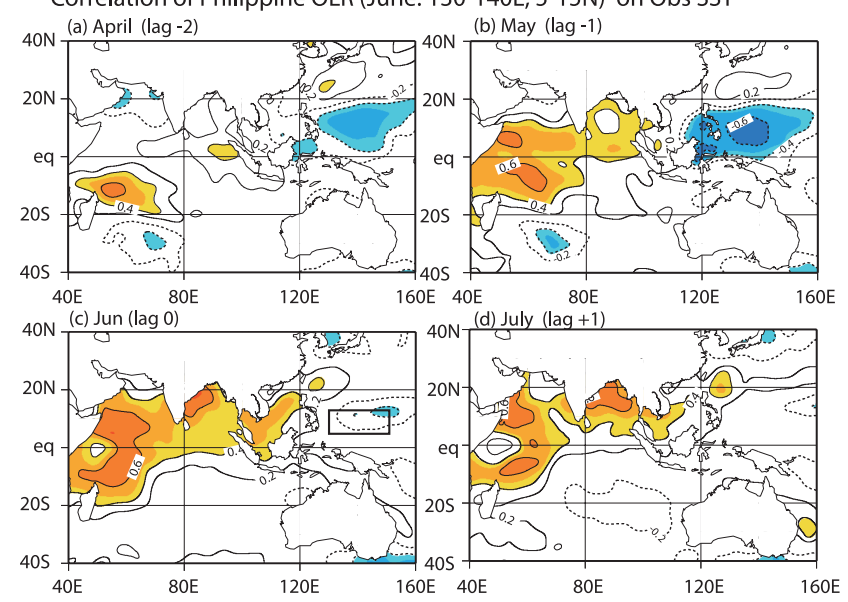

Fig. 1. Correlation between OLR anomalies around the Philippine $\left(130^{\circ} \mathrm{E}-140^{\circ} \mathrm{E}, 5^{\circ} \mathrm{N}-15^{\circ} \mathrm{N}\right)$ during June and lagged SST anomalies for the period 1979-2002 (shading; interval 0.1, contours; interval 0.2). The correlation coefficient greater (less) than $0.4(-0.4)$ is shaded red (blue). The reference OLR is denoted as a solid square.

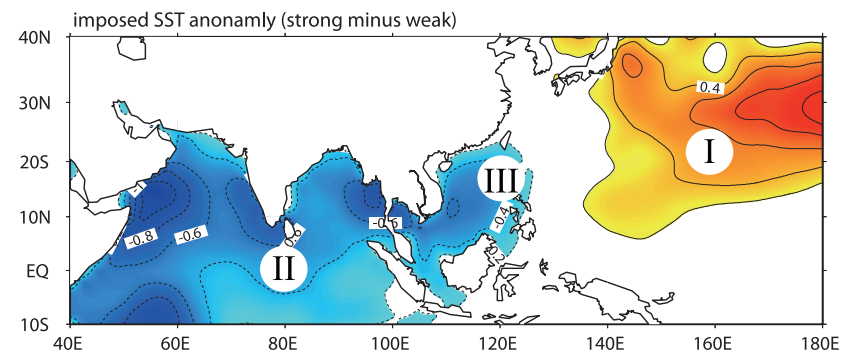

Fig. 2. Prescribed SST anomalies $\left({ }^{\circ} \mathrm{C}\right)$ in the experiments during June. Red (blue) shading denotes the SST anomalies greater (less) than $0.2(-0.2){ }^{\circ} \mathrm{C}$. The Roman numerals reveal the imposed SST anomalies in the (I) P-WNP, (II) N-NIO and (III) NSCS run.

pointed out the importance of the east-west gradient of SST anomalies across the Philippines is intimately associated with convective activity in that vicinity.

As a forcing from atmosphere to ocean, above studies reveal the impact of the enhanced/reduced monsoon westerly on the SST over the tropical regions, paying attention to the intensity of ASM itself. However, how the zonal gradient of the SST anomalies between the NIO and the warm pool region east of Philippines give feedback to the local convection and circulation over the region is not adequately clear. Keeping these in mind, our objective in this study is to reveal the role of the east-west gradient on the interannual fluctuations of WNP monsoon rainfall during the early summer from the aspect of ocean-to- 


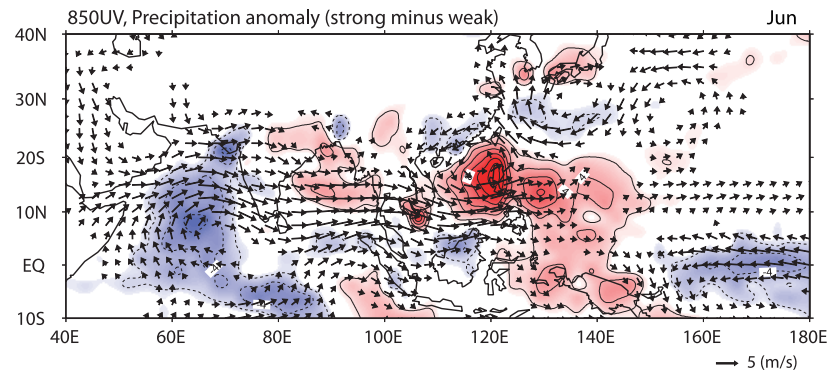

Fig. 3. Composite difference in observed monthly mean precipitation and $850 \mathrm{hPa}$ wind between strong and weak monsoon years for June. Contour interval is $2 \mathrm{~mm} \mathrm{day}^{-1}$. Red (blue) shading denotes the precipitation anomalies greater (less) than $1(-1) \mathrm{mm}_{\mathrm{day}}{ }^{-1}$.

atmosphere feedback. Section 2 presents a brief description of our model and the experimental design. Section 3 examines dynamical response of the convection in the AGCM to SST anomalies in the Indian Ocean and WNP. Section 4 summarizes our conclusions.

\section{Model and experimental design}

\subsection{Model and data}

The model we use is AGCM in MRI-CGCM2.3, an airsea coupled model (CGCM) developed by Meteorological Research Institute in Japan (Yukimoto et al. 2006). The AGCM is a global spectral model, which we ran at T42 resolution and with 30 sigma-pressure coordinate levels in the vertical with model top at $0.4-\mathrm{hPa}$. The nonlinear terms and the parameterized physical processes are calculated on a $128 \times 64$ Gaussian grid with a horizontal resolution of about $2.8^{\circ} \times 2.8^{\circ}$. The AGCM is forced with daily SST interpolated from monthly SST. The spatial structure and magnitude of rainfall and low-level circulation over the Asian-Pacific summer monsoon regions are simulated reasonably well.

We utilized monthly-mean NOAA Interpolated OLR and extended reconstructed SST version 2 (ERSSTv2; Smith and Reynolds 2004) for 1979-2002. Also used are the NCEP/NCAR (National Center for Environmental Prediction/National Center for Atmospheric Research) atmospheric reanalysis data (Kalnay et al. 1996) and monthly precipitation derived from CPC Merged Analysis of Precipitation (Xie and Arkin 1996) for the comparison between the model results and observations.

\subsection{Experimental design}

The seasonal consequences over the WNP monsoon are well corresponded to the zonal gradient in SST between the NIO and WNP through the local air-sea interactions. Ueda (2005) pointed out that the east-west asymmetric heat exchange at the ocean surface across the Philippines, in response to eastward intrusion of the summer monsoon westerlies toward the WNP, can produce climatological zonal gradient of SST and ensuing delayed onset of the WNP monsoon. It is conceivable that these features are also valid for interannual fluctuations. Therefore, the model experiments reported here focus on the early summer (June), which leads the mature phase of the WNP monsoon.

Figure 1 shows the lag correlations between the area-averaged outgoing long-wave radiation (OLR) anomalies around the Philippines $\left(130^{\circ} \mathrm{E}-140^{\circ} \mathrm{E}, 5^{\circ} \mathrm{N}-\right.$ $15^{\circ} \mathrm{N}$ ) in June and SST anomalies over the NIO and WNP during the April to July. Negative correlation indicates that warmer SST is related to anomalously strong convection, as indicated by negative OLR anomalies.
The remarkable characteristic of Fig. 1 is the presence of positive correlations over the NIO-SCS SST, as well as the underlying negative correlation. These structures during April through June bear considerable resemblance with the strong minus weak monsoon regime composite (Kawamura et al. 2001). Especially in June, the positive correlation has the largest amplitude over NIO without the negative in the WNP. In contrast with this, the SST anomalies in July do not exhibit the significant correlation, implying that the SST anomalies in the region during the summer are attributed to the atmospheric variation (Wang et al. 2005). Thus, the question we will address in this study is how these SST anomalies during early summer play a role in the local atmospheric circulation and convective activity around the Philippines. To examine the possible role of the SST gradient to the interannual fluctuations of convective activity around the Philippines, we conducted AGCM experiments by imposing the anomalous east-west gradient of SST.

Four simple experiments are conducted that are designed to yield a straightforward answer to the question. We extracted most prominent five strong monsoon years $(1981,1984,1985,1990$ and 1999) and weak years $(1979,1983,1987,1992$ and 1997) by use of meridional temperature gradient (MTG: Kawamura 1998) index at the period from 1979 to 2002. This index defined as the meridional difference in area-averaged upper-tropospheric $(200-500 \mathrm{hPa})$ thickness between the Tibetan Plateau $\left(50-100^{\circ} \mathrm{E}, 20-40^{\circ} \mathrm{N}\right)$ and the NIO $\left(50-100^{\circ} \mathrm{E}, 0-20^{\circ} \mathrm{N}\right)$ regions. These years are also consistent with the Webster and Yang's (1992) index, which reasonably captures the "broad-scale monsoon circulation" as well as the MTG. The anomalies are deviation from the climatological mean $(1970-1999)$. In the positive WNP (P-WNP) runs, warm SST anomalies are imposed in the WNP (Fig. 2), and climatological SST are imposed elsewhere. The negative NIO (N-NIO) and SCS (N-SCS) runs are similar to the P-WNP run, but for the WNP anomalies are replaced by the climatology and the composited negative SST anomalies are inserted for NIO and SCS. Outside of the region, we used the climatological SST, derived from the 50-yr mean of the ERSST.v2. PN-PI runs are prescribed both the positive and negative SST anomalies for WNP, NIO and SCS, respectively. For each forcing scenarios, the model is run for 1 yr from January thorough December. Except for June, the climatological SST are prescribed through the year. To account for the atmospheric sensitivity to the initial conditions, a 10-member ensemble approach is conducted for each forcing scenario. We made changes only in the initial conditions selected from 10 snapshots of the climatological control run in preserving the same SST forcing. To confirm the nonlinearity of the tropical atmosphere in response to SST anomalies, we also conducted the four experiments by use of the opposite SST anomalies. The simulated results reveal the reversed features approximately. Thus, we omit the reversed experiments to make the thesis short.

\section{Influence of the SST anomalies on the Philippine convection}

First, we showed the composite difference in observed precipitation with $850-\mathrm{hPa}$ wind between strong and weak monsoon years for June (Fig. 3), for comparison with the results of the numerical experiments. We note that enhanced precipitation extends zonally from the SCS to the warm pool region of the WNP. An anomalous cyclonic circulation is well organized to the northwest of the center of the positive precipitation anomalies as a consequence of the Rossby wave response to the convective heating. The most conspicuous feature in the Fig. 3 is domination of enhanced westerlies from the NIO penetrating into the warm pool 
(a) Precip., 850hpa-UV (anomaly) PN-PI run

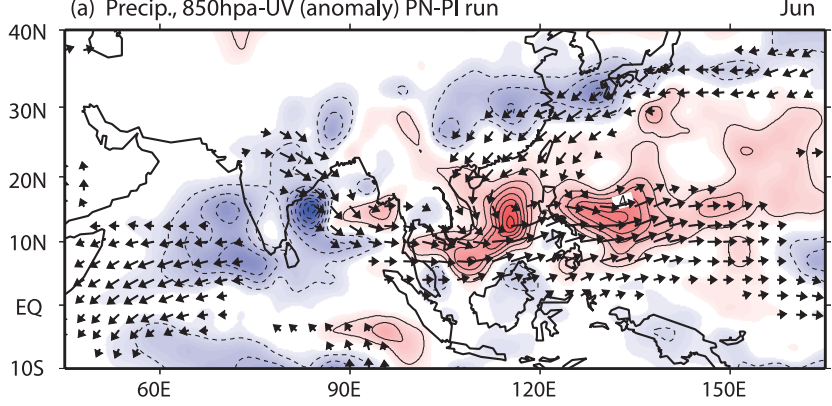

(b) Precip., 850hpa-UV (anomaly) P-WNP run

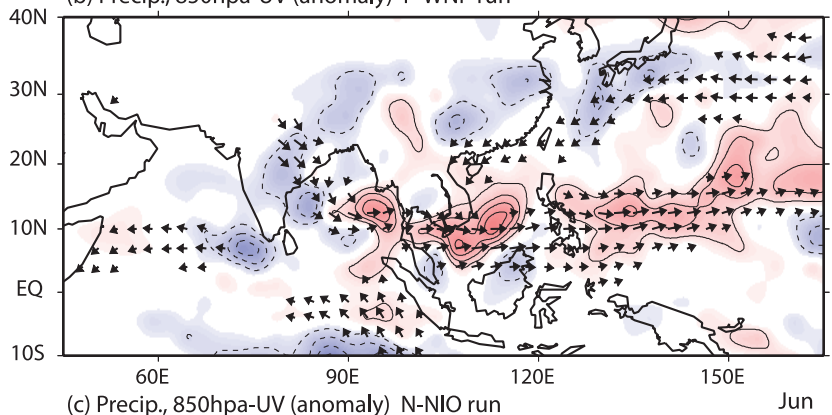

(c) Precip., $850 \mathrm{hpa}-\mathrm{UV}$ (anomaly) N-NIO run

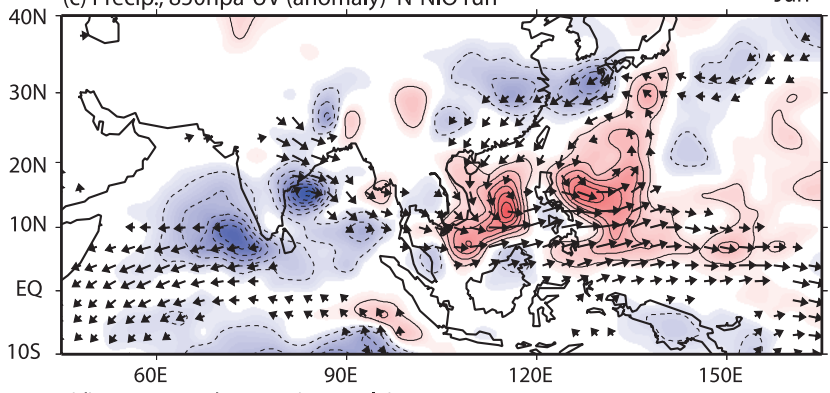

(d) Precip., 850hpa-UV (anomaly) N-SCS run

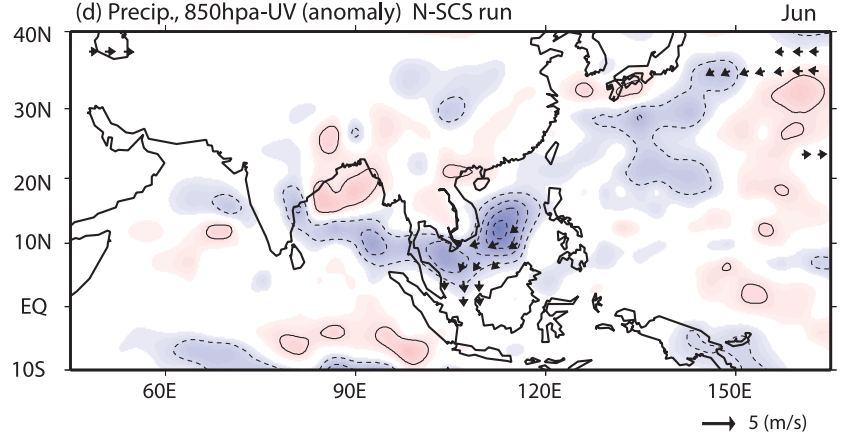

Fig. 4. Composite anomalies of the precipitation and $850 \mathrm{hPa}$ wind anomalies in June for (a) the PN-PI, (b) the P-WNP, (c) the N-NIO and (d) the N-SCS run. Shaded area denotes precipitation greater (less) than $0.5(-0.5) \mathrm{mm} \mathrm{day}^{-1}$. Contour interval is $1 \mathrm{~mm}$ day $^{-1}$.

region of the WNP along a latitudinal band between $10^{\circ}$ and $20^{\circ} \mathrm{N}$. The negative SST anomalies are collocated with the intensified low-level wind anomalies. Despite of the enhanced evaporation at the NIO (Kawamura et al. 2001), the precipitation anomalies over the $\mathrm{BOB}$ are significantly weaker than those of the WNP.

Figures 4 represents the composite anomalies of the precipitation in the NIO and WNP, which will shed light on the remote and local impact of SST anomalies that can be directly compared with the PN-PI, P-WNP, N-NIO and N-SCS run. The results presented here are based on the ensemble averages over ten individual integrations. The anomalies are obtained by difference from the climatology of 40-year AGCM control run. For additional information, we also plot the $850-\mathrm{hPa}$ wind anomalies during the June. The common feature of the precipitation in PM-PI, P-WNP and N-NIO runs is enhanced (suppressed) convection anomalies over the prescribed SST over the WNP (NIO), which can be attributed to the increase (decrease) in the local convective instability and decrease (increase) in the sea level pressure (e.g., Lindzen and Nigam 1987). The PN-PI (Fig. 4a) runs aim in assessing the effect of the SST anomalies by comparing with the observation. The simulated anomalies over the Arabian Sea through the WNP reproduce the fundamental observational features (Fig. 3) in terms of both the amplitude and spatial distribution, although the precipitation anomalies over the Bay of Bengal (BOB) show the opposite sign. The 850$\mathrm{hPa}$ wind vectors are directed toward the WNP SST anomalies in the BOB through the WNP. The anomalous cyclonic circulation over the East China Sea is also reproduced via a baroclinic Rossby wave response to anomalous convective heating over the Philippines.

The P-WNP (Fig. 4b), N-NIO runs (Fig. 4c) and N-SCS runs (Fig. 4d) aim in examining in situ versus remote SST influences on the precipitation around the Phillipines. Except for the increase in precipitation over the Philippines, the large-scale response of the PN-PI run is similar to the combination of the P-WNP and N-NIO run. In the P-WNP run, there are positive precipitation anomalies over the WNP in response to the underlying warm SST anomalies. The anomalous convective heating over the WNP is corresponding to the monsoon westerlies along $10^{\circ} \mathrm{N}$ over the BOB through the SCS. The enhanced monsoon westerlies act to strengthen the convergence around the Philippines, thereby possibly providing a positive feedback for the growth of anomaly. It is also conceivable that the low-level moisture intrusion, accompanied by the enhanced westerlies, is also leading to substantial increase in convection over the BOB through the SCS.

Figure $4 \mathrm{c}$ shows the precipitation response in the $\mathrm{N}$ NIO run. The distribution of the precipitation anomalies in the N-NIO run is quite similar to the PN-PI run, although the anomalies reveal relatively weak signal. The most striking feature in the N-NIO run is the enhancement of precipitation over the WNP as well as those of suppression over the NIO. A band of enhanced precipitation eastward of $110^{\circ} \mathrm{E}$ occupies the warm pool region along the $10^{\circ} \mathrm{N}$ while reduced precipitation covers the NIO, especially $\mathrm{BOB}$ and central-eastern Arabian Sea. Although the N-SCS run reveal the negative precipitation anomalies over the SCS, the amplitude of the anomalies are relatively weak in comparison with the N-NIO run, and their horizontal distributions are confined to the limited are (Fig. 4d). Therefore, the SCS SST anomalies can weaken the impact of the PWNP and N-NIO SST anomalies in some extent.

The N-NIO run shows anomalous eastward moisture flux from the BOB through the Philippine Sea (not shown). One possible explanation is probably related to the moisture flux associated with the monsoon westerly over the region and the enhanced in situ evaporation at the region. The surface evaporation at the SCS-WNP $\left(105^{\circ} \mathrm{E}-135^{\circ} \mathrm{E}, 5^{\circ}-20^{\circ} \mathrm{N}\right)$ in the N-NIO run is about $1.9 \times$ $10^{7} \mathrm{~kg} / \mathrm{s}$, while that of the P-WNP run is about $0.8 \times$ $10^{7} \mathrm{~kg} / \mathrm{s}$. We also calculate the vertical integrated zonal moisture flux anomaly summarized $5^{\circ}$ to $20^{\circ} \mathrm{N}$ along the $105^{\circ} \mathrm{E}$. In the case of the N-NIO run, the moisture intrusion into the SCS is $3.9 \times 10^{7} \mathrm{~kg} / \mathrm{s}$. By contrast, the PWNP run simulate $2.6 \times 10^{7} \mathrm{~kg} / \mathrm{s}$. These results imply that the WNP convection is sensitive to the spatial distribution of NIO SST anomalies as well as the in situ SST anomalies. Rossby responses of the SCS-WNP convection also act to reduce the climatological southeasterly, which transfers a large amount of moisture from the tropics to East Asia. This possibly induces a positive feedback to further increase the moisture convergence 
around the Philippines. The reduced moisture transport from the SCS-WNP to East Asia is about $3.2 \times 10^{7} \mathrm{~kg} / \mathrm{s}$ (summarized $105^{\circ}$ to $135^{\circ} \mathrm{E}$ along the $20^{\circ} \mathrm{N}$ ) in the N-NIO run. Thus, both of the eastward and southward moisture intrusions contribute to the precipitation around the region.

The model-derived findings presented here illustrate that the ocean-to-atmosphere feedbacks on the monsoon region could contribute to the rainfall signal over the WNP during the early summer. We speculate that the enhanced moisture intrusion and the convergence are due to the effect of the surface pressure gradient due to the imposed SST anomalies, which contribute to the low-level flow and ensuing convergence in the tropics. As indicated in Lindzen and Nigam (1987) by using the simple one-layer model of the cumulus boundary layer, the surface pressure gradients due to the SST gradients contribute to the low-level convergence in the tropics. The surface pressure gradients in relation to the cold SST anomalies may enhance the low-level westerly at the eastern boundary of the NIO basin. In addition, presumably, the positive feedback in response to the enhanced latent heat release around the Philippines significantly amplifies the remote forced precipitation anomalies. Presented above is just a speculation, which calls for further investigation to reveal the interannual variation of the air-sea coupled system on the monsoon region. Different experimental design will cover these aspects.

\section{Concluding remarks}

In this study, we conducted a set of experiments by using an AGCM, to reveal the relative importance of the WNP-SCS versus NIO SST anomalies in determining the convective activity around the Philippines in June. In addition to the in situ warm SST anomalies in the WNP, the remote cool SST anomalies in the NIO also strengthen the Philippine convection, which is induced by anomalous westerlies penetrating from BOB thorough the WNP. This causes enhanced eastward moisture transport from the BOB to the WNP, thereby inducing the intensification of the convection around the Philippines. Thus, the WNP monsoon rainfall is sensitive to the spatial distribution of NIO SST anomalies as well as the in situ SST anomalies.

Of course, these results do not imply that the SST forces the atmosphere in a unilateral way. The imposed SST anomalies are consistent results of the impact from atmosphere-to-ocean in the strong (weak) monsoon regime that give rise to the SST cooling (warming) over the NIO-SCS. In this study, we confirm the potential effect of the resulted SST anomalies to the localization of the Philippines convection, as ocean-to-atmosphere feedback. Although it is conceivable that the NIO SST is basically passive to the atmospheric modulation, the feedback effects are indispensable to understand the distribution of the precipitation anomalies. The speculation obtained from this study has a substantial need for the inclusion of the air-sea coupled system to improve the seasonal prediction of the East Asia summer monsoon.

Very recently, Wang et al. (2005) reveal a negative simultaneous correlation between the observed precipitation anomalies and the underlying SST anomalies in the WNP during the boreal summer. Kobayashi et al. (2005) also pointed out that the relationship between the precipitation and in situ SST are dependent on the monsoon seasonality. In addition to the seasonal dependence of the local air-sea interaction, we also strengthen the importance of the remote air-sea interaction to understand the localized convection around the Philippines. It should be noted here that the convective activity in June are well correlated with the in situ SST anomalies during the spring (Fig. 1a, b). In contrast with this, those in the summer reveal the negative correlation in the NIO with the lack of WNP (Fig. 1d). Further investigation in air-sea coupled view is required to understand the seasonal dependence of the air-sea interaction in the WNP.

\section{Acknowledgments}

Prof. A. Kitoh and Dr. O. Arakawa are acknowledged for providing the model source code and offering valuable suggestions on its use. This research was supported by Grants-in-Aids for Young Scientists (B) (15740288) from the Japanese Ministry of Education, Science, Sports and Culture and Core Research for Evolutional Science and Technology (JST/CREST).

\section{References}

Chandrasekar, A., and A. Kitoh, 1998: Impact of localized sea surface temperature anomalies over the equatorial Indian Ocean on the Indian summer monsoon. J. Meteor. Soc. Japan, 76, 841-853.

Kalnay, E., and co-authors, 1996: The NCEP/NCAR 40-year reanalysis project. Bull. Amer. Meteor. Soc., 77, 437-471.

Kawamura, R., 1998: A possible mechanism of the Asian summer monsoon-ENSO coupling. J. Meteor. Soc. Japan, 76, 1009-1027.

Kawamura, R., M. Sugi, T. Kayahara, and N. Sato, 1998: Recent extraordinary cool and hot summers in East Asia simulated by an ensemble climate experiment. J. Meteor. Soc. Japan, 76, 597-617.

Kawamura, R., T. Matsuura, and S. Iizuka, 2001: Interannual atmosphere-ocean variations in the tropical western North Pacific relevant to the Asian summer monsoon-ENSO coupling. J. Meteor. Soc. Japan, 79, 883-898.

Kobayashi, C., S. Maeda, A. Ito, Y. Matsushita, and K. Takano, 2005: Relation between SSTs and predictability of seasonal mean precipitation over the western tropical Pacific. J. Meteor. Soc. Japan, 83, 919-929.

Lindzen, R. S., and S. Nigam, 1987: On the role of sea surface temperature gradients in forcing low-level winds and convergence in the tropics. J. Atmos. Sci., 44, 2418-2436.

Nakazawa, T., 2001: Suppressed tropical cyclone formation over the western North Pacific in 1998. J. Meteor. Soc. Japan, 79, 173-183.

Smith, T. M., and R. W. Reynolds, 2004: Improved extended reconstruction of SST. J. Climate, 17, 2466-2477.

Terao, T., and T. Kubota, 2005: East-West SST contrast over the tropical oceans and post El Niño western North Pacific summer monsoon, Geophys. Res. Lett., 32, L15706, doi:10.1029/2005GL023010.

Ueda, H., 2005: Air-sea coupled process involved in stepwise seasonal evolution of the Asian summer monsoon. Geograph. Rev. of Japan, 78, 825-841.

Wang, B., R. Wu, and X. Fu, 2000: Pacific-East Asia teleconnection: How does ENSO affect East Asian climate? J. Climate, 13, 1517-1536.

Wang, B., Q. Ding, X. Fu, I.-S. Kang, K. Jin, J. Shukla, and F. Doblas-Reyes, 2005: Fundamental challenge in simulation and prediction of summer monsoon rainfall. Geophys. Res. Lett., 32, L15711, doi:10.1029/2005GL022734.

Webster, P. J., and S. Yang, 1992: Monsoon and ENSO: Selectively interactive systems. Quart. J. Roy. Meteor. Soc., 118, 877-926.

Xie, P., and P. A. Arkin, 1996: Global precipitation: a 17-year monthly analysis based on gauge observations, satellite estimates, and numerical model outputs. Bull. Amer. Meteor. Soc., 78, 2539-2558.

Yukimoto, S., and co-authors, 2006: Present-day climate and climate sensitivity in the Meteorological Research Institute coupled GCM Version 2.3 (MRI-CGCM2.3). J. Meteor. Soc. Japan, 84, 333-363.

Manuscript received 30 October 2006, accepted 2 December 2006 SOLA: http://www.jstage.jst.go.jp/browse/sola/ 